\title{
A Study on Spatial-Temporal Rainstorm Risk at Civil Airports in China
}

\author{
Xiaomei Guo ${ }^{1,2}$, Xiaobing $\mathrm{Hu}^{1,2}$, Hang $\mathrm{Li}^{1,2}$, Zhen $\mathrm{Xu}^{1}$ \\ ${ }^{1}$ Academy of Disaster Reduction and Emergency Management, Beijing Normal University, Beijing 100875, China \\ ${ }^{2}$ State Key Laboratory of Earth Surface Processes and Resource, Beijing Normal University, Beijing 100875, China
}

Received 30 June 2015

Accepted 5 August 2015

\begin{abstract}
Based on daily precipitation data of 174 meteorological stations near civil airports in China, flight data over the same period (1994-2013) and other relevant airport data, this paper carries out a study on risk analysis of rainstorm at Chinese civil airports. We use the platform of ARCGIS, analyze the four essential factors of disasters, i.e., rainstorm hazard, vulnerability, exposure and the capability of disaster prevention and mitigation, combine the traditional model of meteorological disaster risk assessment and characteristics of Chinese civil aviation, and then develop monthly rainstorm disaster risk zoning maps for civil airports in China. The results can provide useful information to daily operations of civil aviation of China, as well as to planning and management of civil aviation systems, in order to better mitigate the impact of heavy rains on daily functions of civil aviation of China.
\end{abstract}

Keywords: Civil airport; rainstorm disaster; risk assessment; risk zoning; spatial-temporal analysis

\section{中国机场暴雨灾害风险时空分析 \\ 郭晓梅 ${ }^{1,2}$, 胡小兵 ${ }^{1,2}$, 李航 ${ }^{1,2}$, 许珍 ${ }^{1}$}

1. 减灾与应急管理研究院, 北京师范大学, 北京 100875 , 中国

2. 地表过程与资源生态国家重点实验室, 北京师范大学, 北京 100875 , 中国

\begin{abstract}
摘要：基于机场附近 174 个气象站点 1994-2013 年的逐日降水数据、同期实时航班数据和机场吞吐量等相 关资料, 本文展开中国 174 个机场暴雨灾害风险的初步研究。在 ARCGIS 平台上, 对中国机场的暴雨危险性、 机场脆弱性、暴露性和防灾减灾能力等 4 方面进行分析, 结合传统气象灾害风险评估模型和中国民用航空 特点，得到中国机场不同月份暴雨灾害风险等级区划图。结果可为中国民航日常运营提供依据，以指导民 航的规划和建设运营，最大限度降低暴雨带来的灾害损失。
\end{abstract}

关键词: 中国机场；暴雨灾害; 风险评估; 风险区划; 时空分析

\section{1. 引言}

在全球气候变化的大背景下, 气象灾害风险大 大增加。IPCC 指出, 全球自然灾害中 $80 \%$ 以上是气 象灾害或者其衍生灾害 ${ }^{[1]}$ 。我国近 20 年(1994-2013 年）气象灾害灾情分析表明，死亡人口和直接经济 损失占所有自然灾害的比例多年平均值分别为 $55 \%$

作者简介: 郭晓梅 (1990-), 女, 硕士, 研究方向为自然 灾害. E-mail: 201321480021@bnu.edu.cn
和 $87 \%^{[2]}$ 。全球灾害数据库 (EM-DAT) 统计表明, 降水, 洪涝, 台风等灾害是中国主要的气象灾害, 而且呈上升趋势。随着中国经济快速发展, 民用航 空运输业也日新月异, 根据 2013 年中国民航统计公 报显示: 2013 年全行业完成运输总周转量 671.72 亿吨公里, 比增长 $10.9 \%$; 全国民航运输机场完成 旅客吞吐量 7.54 亿人次, 固定资产投资总额达 1452.2 亿元。气象灾害已经成为影响民航可持续发 展的重要因素, 暴雨, 台风, 雪灾, 沙尘暴等灾害 
天气都成为中国民航主要的致灾因子, 结果轻则是 直接导致机场和航路关闭, 并可能造成机场和航路 导航设备的损坏; 严重则造成大面积航班延误, 甚 至引发灾难性的航空事故。例如, 2008 年我国南方 遭遇百年罕见的雪灾, 造成全国共 30 多个机场间 断性关闭, 航班大面积延误、停飞, 导致近千万旅 客滞留机场; 2000 年武汉空难, 机组、旅客共遇难 51 人, 原因是飞机在盘旋过程中可能遭遇雷击或者 风切变; 2002 年 4 月 15 日, 中国国航由于大暴雨, 加上操作不当, 发生“金釜山空难”, 遇难 128 人。 我国灾害性天气具有全天候、全年性和突发性等特 征, 而且地方性特点明显 ${ }^{[3-4]}$ 。春季多风、西北地区 常有扬沙, 夏季东部地区多台风和雷暴, 秋季有雷 暴, 冬季北部和西部多大风和降雪, 其中大风、大 雾、降雪、扬沙、雷暴等恶劣天气条件严重影响航 班的准点率和飞机飞行安全。根据美国航空数据网 站 FLIGHTSTATS 公布的数据 ${ }^{[5]} 2014$ 年 10 月份中 国的航空公司的准点率最高的是中国国航, 准点率 $73.3 \%$, 南方航空, 东方航空的准点率则更低, 为 $68 \%$ 左右。根据中国民航局统计数据显示， 2013 年 全国航空公司共执行航班 278.0 万班次, 不正常航 班占 76.9 万班次, 其中天气原因 $21.8 \%$ 。航班延误, 取消等不正常航班给旅客出行等带来重大影响, 2013 年收到的旅客投诉同比 2012 年增加 13.66\%, 甚至由于航班延误而引发旅客打砸机场的事件。气 象灾害已对民航的发展构成严重威胁。民航气象是 航空业正常运行的保障 ${ }^{[6]}$, 全面地、系统地进行民 航气象灾害风险研究对我国民用航空业的可持续发 展及安全运营具有巨大的战略意义。

灾害学作为一门交叉学科, 20 世纪伴随着保 险业发展在一些发达国家迅速发展。直到 60 年代, 自然灾害的研究仍然主要限于灾害机理以及灾害预 测, 侧重于灾害形成条件的调查和活动过程的考察。 一些较发达国家在 70 年代开始进行灾害风险的评 估工作。美国内务部的调查所等相关部门对加利福 尼亚、旧金山等地区的滑坡、地震等 10 种自然灾害 进行了风险评价与损失评估, 其中包括风县风、龙卷 风、风暴潮等气象灾害风险评估 ${ }^{[7]}$ 。Lavalle(2005) 提出 JRC 风险评估法, 对欧洲 10 个国家进行了天 气灾害的综合风险评估 ${ }^{[8]}$ 。我国的自然灾害评价工 作起步较晚, 90 年代后, 台风、沙尘暴等气象灾害 的风险评估才开始受到较多重视。气象灾害风险研 究则在某些具体行业中的开展了应用研究。在对天
气、气候变化最为敏感的农业研究的文献较多, 如: 李世奎等较早提出了较完善的农业气象灾害风险区 划指标体系和农业气象灾害风险评价模型 ${ }^{[9-10]}$; 高 晓蓉等基于气象灾害四要素理论，对东北地区玉米 的主要气象灾害风险评价模型进行了研究 ${ }^{[11]}$; 于飞 等基于信息扩散理论对贵州夏旱、倒春寒等八种主 要气象灾害进行不确定风险分析 ${ }^{[12]}$ 。基础设施中与 气象密切相关的行业的气象灾害风险评价也有了初 步的探索。如: 武永峰等基于地 GIS 技术和灰色综 合评价法，建立了公路交通暴雨风险评价模型，对 湖南省公路的暴雨风险进行了定量评估 ${ }^{[13]}$; 付桂琴、 张文宗根据 1983-2008 年河北气象灾害灾情数据, 将河北电网气象灾害风险分高、中、低三个等级 ${ }^{[14]}$ 。 天气原因的航班延误、暴雨灾害对民航的重大影响 引起人们的广泛关注，但民航灾害风险相关的研究 仍然较少。Janic(2000)以火山灰为例 ${ }^{[15]}$, 对欧洲民 航进行了风险安全评估；李铭等基于民航雷达站的 雷电定位数据, 结合地形地貌特征进行了雷击风险 区划 ${ }^{[16]}$; 张建等 ${ }^{[17]}$ 分析了民航广汉机场的气象能见 度特征。民用航空业的气象灾害风险研究，目前仅 限于民航灾害风险分析和气象预报预警阶段 ${ }^{[18-20]}$, 民航气象灾害风险评价理论和方法模型仍在探索中。

传统的灾害学研究比较偏重于巨灾大灾对物理 承灾体造成的损失，例如，地震台风造成机场的基 础设施受到破坏。这种偏重于巨灾大灾和物理损失 的灾害研究思路对民航业的安全建设当然非常重要, 但却不易受到民航相关人员的认可和重视，因为民 航工作人员和旅客所重点关注的为更经常发生的 （相对于巨灾大灾）恶劣天气事件对民航运输服务 功能的影响。例如, 硬件条件差的地方小机场, 虽 然对巨灾大灾的脆弱性很高，但其服务功能方面的 脆弱性未必就高（因为旅客流量小，很容易疏导， 从而暴露度小); 而硬件条件最好的国际枢纽大机场, 虽然对巨灾大灾的物理抵抗能力很强，可是一场暴 雨却可能导致大规模的服务功能混乱。因此, 要开 展能得到民航行业认可的灾害风险研究, 就必须转 变思路, 从传统的偏重于巨灾大灾和物理损失, 到 强调和研究日常性恶劣天气事件所造成的服务功能 损失。如何才是好的转变思路的研究方法, 本文就 是要进行这样的尝试。本文在现有气象灾害风险评 价与灾害综合风险管理相关理论研究的基础上, 充 分考虑民用航空的行业特点, 对我国主要机场的暴 雨灾害展开定量的、偏重于功能损失的风险评估。 在全球民航快速发展, 气候变化加剧的复杂背景下, 本文以暴雨灾害为例，对民航气象灾害综合风险评 估模型进行初步探索，充分考虑机场服务功能脆弱 
性、暴露度和防灾减灾能力。风险值与气象指标相 比更加直观且更具建设性, 可以为民航相关行业决 策和民众出行提供依据。风险模型随时利用机场天 气情况计算出不同区域的灾害风险值, 结合当今发 达的网络平台, 实时更新; 而中长期的气象灾害风 险等级可以为机场建设标准提供参考依据。航空公 司可以根据短期的气象灾害风险区划慎重地调整和 安排不同地区的飞机类型和数目, 以降低安全隐患 和节省资金。游客也可以根据风险等级选择出行与 否, 或者是否买保险等。文章第一部分为引言; 第 二部分介绍了使用的资料和方法; 第三部分, 以月 为单位, 分析与计算得到不同月份中国机场的暴雨 危险性、机场暴露度、脆弱性和防灾减灾能力, 并 且基于ARCGIS平台, 对暴雨灾害四要素进行区划; 第四部分, 结合传统气象灾害风险评估模型计算得 到中国174个机场的暴雨灾害综合风险值和区划图; 第五、六部分进行了总结和讨论。

\section{2. 资料和方法}

\section{1. 资料}

1) 灾情资料: 根据《中国气象灾害大典: 综合卷》 收集了全国 2005-年暴雨、洪涝、沙尘暴等气象 灾害。

2) 暴雨资料: 选取了全国 174 个机场附近的气象 站 1994-2013 年 20-20 时日值降水数据。

3) 实时航班数据: 2013 年全国机场航班实时数 据。

4) 机场资料: 2013 年 174 个机场的飞行区等级数 据、抗灾投入、机场货邮吞吐量、旅客吞吐量 等。中国民用航空局 [21] http://www.caac.gov.cn/H1/H2/。

2.2. 研究方法说明

1) 自然断点分级法: (Natural breaks classification) 用统计公式来确定属性值的自然聚类, 公式的 功能就是减少同一级的差异, 增加级间的差异, 其公式为:

$$
S S D_{i-j}=\sum_{k=1}^{j}\left(A[k]-\bar{n}_{i-j}\right)^{2}, \quad(1 \leq i<j \leq N)
$$

式中, $A$ 为一个数组 (数组长度为 $N) ; \bar{n}$ 为每 个等级中的平均值。

2) 层次分析法 ${ }^{[22]}$ : (Analytic hierarchy process, 简 称：AHP）该方法是对一些较为复杂又难以 完全定量分析的问题做出决策的简易方法, 主要包括以下四个步骤:
(1) 指标体系的层次结构建立, 根据灾害系统等 相关理论将指标层次化，一般分为目标层、 标准层和指标层。

(2) 构造判断矩阵, 根据专家调查结果, 评定该 层次中各有关元素的相对重要程度。本研究 结合“中国机场暴雨灾害风险的指标体系”设 计了“专家打分表”, 采用问卷调查的方式对民 航、气象、灾害等领域的专家及研究人员等 进行问卷调查。问卷发放 60 份, 回收 58 份, 回收率 $96.7 \%$, 有效问卷 56 份, 有效率 $96.6 \%$ 。 采用比例最大原则确定为最终专家打分结果。

(3) 求特征向量和特征根, 用矩阵向量法计算判 断矩阵的最大特征根 $\lambda_{\text {max }}$, 获得每层次的各 指标的权重值。

(4) 一致性检验, 通过一致性比例公式: $C R=C I / R I$ 来检验判断矩阵的权重分配是否合理。其中,

$\mathrm{CI}$ 为一致性指标, $\mathrm{CI}=\left(\lambda_{\max }-\mathrm{n}\right) /(\mathrm{n}-1) ; \mathrm{RI}$ 为 随机一致性指标。当 $\mathrm{CR}<0.10$ 时，认为判断 矩阵具有一致性, 否则, 需对判断矩阵进行 调整。

3）综合指标法：把原始指标数据构造成一组综合 性指标 $X$,

$$
X=\sum_{i=1}^{n} x_{i} w_{i}, \quad i=1,2, \cdots, n
$$

其中, $X$ 为综合指标; $x_{i}$ 为各指标的原始值; $w_{i}$ 为各指标由层次分析法得到的相应权重值。

\section{3. 模型建立}

\section{1. 暴雨灾害风险评估体系的指标构建与计算}

根据史培军对灾害系统论 ${ }^{[23]}$ 的总结，灾害包括 致灾因子, 承灾体和孕灾环境三要素, 而社会经济 环境是孕灾环境的重要组成部分。张继权等 ${ }^{[24]}$ (2007) 在气象灾害的研究中提出气象灾害风险形成除了致 灾因子危险性、承灾体的脆弱性和暴露性外，防灾 减灾能力也是制约和影响气象灾害风险的因素。防 灾减灾能力表示某一区域遭受灾害破坏后，在一定 时期内能够从气象灾害中恢复的程度, 包括：应急 管理能力、减灾投入、资源准备等。防灾减灾能力 越高，可能灾害损失越小，气象灾害风险就越小。 

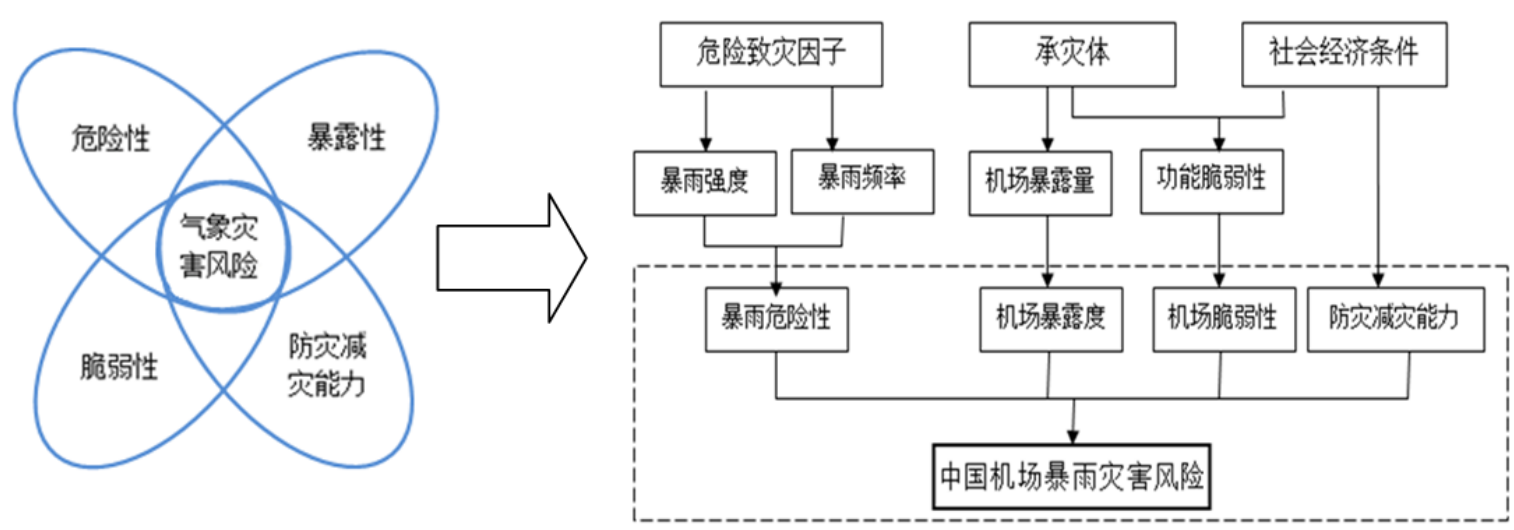

图 1. 中国机场暴雨灾害风险评估概念

风险具有不确定性, 对于民航一个具体行业, 灾害风险涉及影响因素也比较多。本文根据灾害系 统论和相关灾害风险理论, 以致灾因子、承灾体和 孕灾环境三个方面为基础（如图 1), 选取了致灾因 子、暴露性、脆弱性和防灾减灾能力四个指标构建 中国民航暴雨灾害风险评估指标体系。

致灾因子 $(R)$ : 1994-2013 年全国机场附近的气 象站点日降水量 $\geq 50 \mathrm{~mm}$ 记为一次暴雨过程。暴雨灾 害的发生与降水的强度和频次有重大关系, 为了较 科学地定量地分析中国机场致灾因子的危险性强度, 本文选取暴雨频次和暴雨强度为主要评价指标 ${ }^{[25]}$, 统计机场附近各气象站每年的日暴雨过程降水量与 日数, 采用百分位数确定降水对暴雨灾害形成的影 响程度 (即第 60、80、90、95、98 百分位数作为划 分降水量值的位置指标), 将其划分为 1 5 个等级 (如表 1 )。等级越高, 机场暴雨灾害危险性越高。
将暴雨强度 $1 、 2 、 3 、 4 、 5$ 级作为暴雨致灾因子的 权重, 导入到 ArcGIS, 应用空间分析模块中提供的 反距离加权工具 (IDW) 进行空间插值, 得到机场 暴雨灾害危险等级区划图。

暴露程度 $(E)$ : 是指可能受到暴雨威胁的所有人 和财产，如：人员、生命线等。本文用中国民用航 空局提供的 2013 年各个机场的旅客吞吐量、货邮吞 吐量、飞机起降次数等可能受到的暴雨影响程度来 度量暴露性, 运用层次分析法, 指标两两对比基于 民航行业的专业人士问卷调查结果, 计算得到权重 分别为 $0.454 、 0.225$ 和 0.321 。并利用自然断点分级 法将承灾体的暴露性指数分 5 个等级, 并基于 ArcGIS 绘制出中国暴雨暴露性区划图。

脆弱性 $(V)$ : 1994-2013 年间机场在暴雨降水影 响下关闭时间 $\mathrm{T}$ 与该降水时间 $\mathrm{t}$ 的关系

表 1 暴雨过程强度等级标准

\begin{tabular}{|c|c|c|c|c|c|c|c|}
\hline 天数 & $\begin{array}{c}1 \text { 级 } \\
(60--80 \%)\end{array}$ & $\begin{array}{c}2 \text { 级 } \\
(80--90 \%)\end{array}$ & $\begin{array}{c}3 \text { 级 } \\
(90--95 \%)\end{array}$ & $\begin{array}{c}4 \text { 级 } \\
(95--98 \%)\end{array}$ & $\begin{array}{c}\mathbf{5} \text { 级 } \\
\text { (98\%以上) }\end{array}$ & $\begin{array}{c}\text { 样本长 } \\
\text { (/d) }\end{array}$ & $\begin{array}{l}\text { 暴雨值 } \\
(\mathbf{m m})\end{array}$ \\
\hline 1 & $50.5 \leq R<71.0$ & $71.0 \leq R<90.0$ & $90.0 \leq R<114.5$ & $114.5 \leq R<129.0$ & $R \geq 129.0$ & 122 & 50 \\
\hline 2 & $66.3 \leq R<80.4$ & $80.4 \leq R<106.3$ & $106.3 \leq R<125.7$ & $125.7 \leq R<130.4$ & $R \geq 130.4$ & 61 & 50 \\
\hline 3 & $72.9 \leq R<90.5$ & $90.5 \leq R<119.3$ & $119.3 \leq R<133.8$ & $133.8 \leq R<147.1$ & $R \geq 147.1$ & 53 & 50 \\
\hline 4 & $82.1 \leq R<111.2$ & $111.2 \leq R<121.0$ & $121.0 \leq R<154.7$ & $154.7 \leq R<168.4$ & $R \geq 168.4$ & 26 & 50 \\
\hline 5 & $104.5 \leq R<120.2$ & $120.2 \leq R<140.5$ & $140.5 \leq R<162.1$ & $162.1 \leq R<196.0$ & $R \geq 196.0$ & 23 & 50 \\
\hline 6 & $112.1 \leq R<130.1$ & $130.1 \leq R<153.5$ & $153.5 \leq R<190.2$ & $190.2 \leq R<213.7$ & $R \geq 213.7$ & 16 & 50 \\
\hline$\geq 7$ & $125.7 \leq R<147.1$ & $147.1 \leq R<167.4$ & $167.4 \leq R<203.8$ & $203.8 \leq R<221.7$ & $R \geq 221.7$ & 12 & 50 \\
\hline
\end{tabular}




$$
v=\frac{t}{T_{i}}, V=\frac{v}{L_{i}}
$$

式中, $\mathrm{t}$ 是某机场有暴雨当天的计划航班总数, $T_{i}$ 为某机场受当天暴雨影响的非正常航班数 (取消、 返航、延误和迫降等), $v$ 为非正常航班所占比例, $L_{i}$ 为暴雨的时长, $\boldsymbol{V}$ 为某机场的暴雨脆弱性。计算 所得结果用自然断点分级法将承灾体的脆弱性指数 分 5 个等级, 并基于 ArcGIS 绘制出中国暴雨脆弱性 区划图。

防灾减灾能力 $(C)$ : 机场飞行区是飞机地面活动 及停放提供适应飞机特性要求和保证运行安全的构 筑物的统称, 包括: 跑道及升降带、滑行道、停机 坪、地面标志、灯光助航设施及排水系统等, 能较 好的表征一个机场对灾害性天气的防灾减灾能力。 本文把机场的飞行区划等级 3C、4C、4D、4E、4F 划分为 $1 、 2 、 3 、 4 、 5$ 共五级。飞行区划等级与机 场建筑占地面积 $S$, 分别用 0.5 的权重, 计算出中国 174 个机场的防灾减灾能力值。基于 ArcGIS 绘制出 机场防灾减灾能力区划图。

\section{2. 暴雨灾害风险区划与权重确定} 模型为:

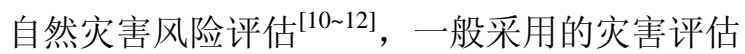

$$
R=H * V
$$

在以上因子定量分析评价基础上, 暴雨灾害风 险指数计算公式如下:

$$
\begin{aligned}
& R=H * E * V *(5-F) \\
& R=H^{w_{i} *} E^{W_{*} *} V^{w_{*} *}(5-F)^{w_{f}} \\
& H=\sum_{i=1}^{5} A_{i}^{*} \boldsymbol{W}_{i} \\
& E=\sum_{i=1}^{3} A_{i}^{*} \boldsymbol{W}_{i}
\end{aligned}
$$

式中, $R$ 表示机场暴雨灾害风险指数， $R$ 值越大, 风险程度越大。 $H, E, V, F$ 分别表示暴雨危险 性、机场的暴露性、机场脆弱性、防灾减灾能力, $W$ 为个评价指标的权重系数, $A$ 为各评价指标的量 化值, $i$ 为评价因子系数。 $H 、 E 、 V 、 F$ 各评价因子 的权重分别为 $w_{h} 、 w_{e} 、 w_{v}$ 、 $w_{f}$, 通过层次分析法 计算获得, 两两对比的指标由专家打分获得。 判断矩阵每一列归一化:

$$
\bar{A}_{i j}=\frac{A_{i j}}{\sum_{k=1}^{m} A_{k j}}, \quad(i, j=1,2, \ldots m)
$$

每一列判断矩阵相加:

$$
\bar{a}_{i}=\sum_{j=1}^{m} \bar{A}_{i j} \quad(i, j=1,2, \ldots m)
$$

对向量 $\bar{a}=\left(\bar{a}_{1}, \bar{a}_{2}, \ldots \bar{a}_{m}\right)$ 作归一化处理:

$$
w_{i}=\frac{\overline{a_{i}}}{\sum_{j}^{m} \overline{a_{j}}}, \quad(i, j=1,2, \ldots m)
$$

式中, $A$ 为评价指标量化值, $i 、 j$ 为相应系数, $w$ 为相应的权重。其中, 计算得到判断矩阵的最大特 征根为 4.017, 一致性检验得 $\mathrm{CR}=0.067<0.1$ 。依次 所得到的 $w_{1}, w_{2}, \cdots, w_{\text {m }}$ 即为所求各评价指标的权 重。通过上述方法, 计算各评价因子的指标权重结 果如表 2 。

最后利用 ArcGIS 中将机场暴雨灾害风险划分 五个等级 (高、较高、中等、较低, 低), 并且用 ArcGIS 空间插值法绘制出中国机场暴雨灾害风险 区划等级图。

表 2 中国机场暴雨风险权重

\begin{tabular}{cll}
\hline 目标层 & 标准层 & 指标层 \\
\hline \multirow{2}{*}{ 中 } & & 级暴雨强度频次 $(0.067)$ \\
国 & & 2 级暴雨强度频次 $(0.133)$ \\
机 & & 3 级暴雨强度频次 $(0.200)$ \\
场 & 级暴雨强度频次 $(0.267)$ \\
暴 & & 5 级暴雨强度频次 $(0.333)$ \\
雨 & 暴露性 (0.295) & 货邮吞吐量 $(0.225)$ \\
风 & & 旅客吞吐量 $(0.454)$ \\
\cline { 2 - 3 } 险 & 脆弱性 (0.147) & 航班数 $(0.321)$ \\
\cline { 2 - 3 } & 防灾减灾能力 $(0.133)$ & 机场脆弱性 \\
\hline
\end{tabular}




\section{4. 结果与分析}

\section{1. 暴雨致灾因子危险性分析}

分析中国综合暴雨强度频次分布图, 可知: 各 级暴雨频次最大地区 6 月份主要在华南一带如: 白 云机场等, 七月、八月随着副热带高压的移动, 中 国雨带也随着移动, 图 7 暴雨危险性变化与这一现 相似。七月末、八月初, 华北、华中地区暴雨比较
频繁, 机场的暴雨危险性也相应增加。

\section{2. 机场暴露性分析}

如图 2, 中国机场 2013 年平均暴露程度图, 旅 客吞吐量、货邮吞吐量和飞机起降次数较多的机场

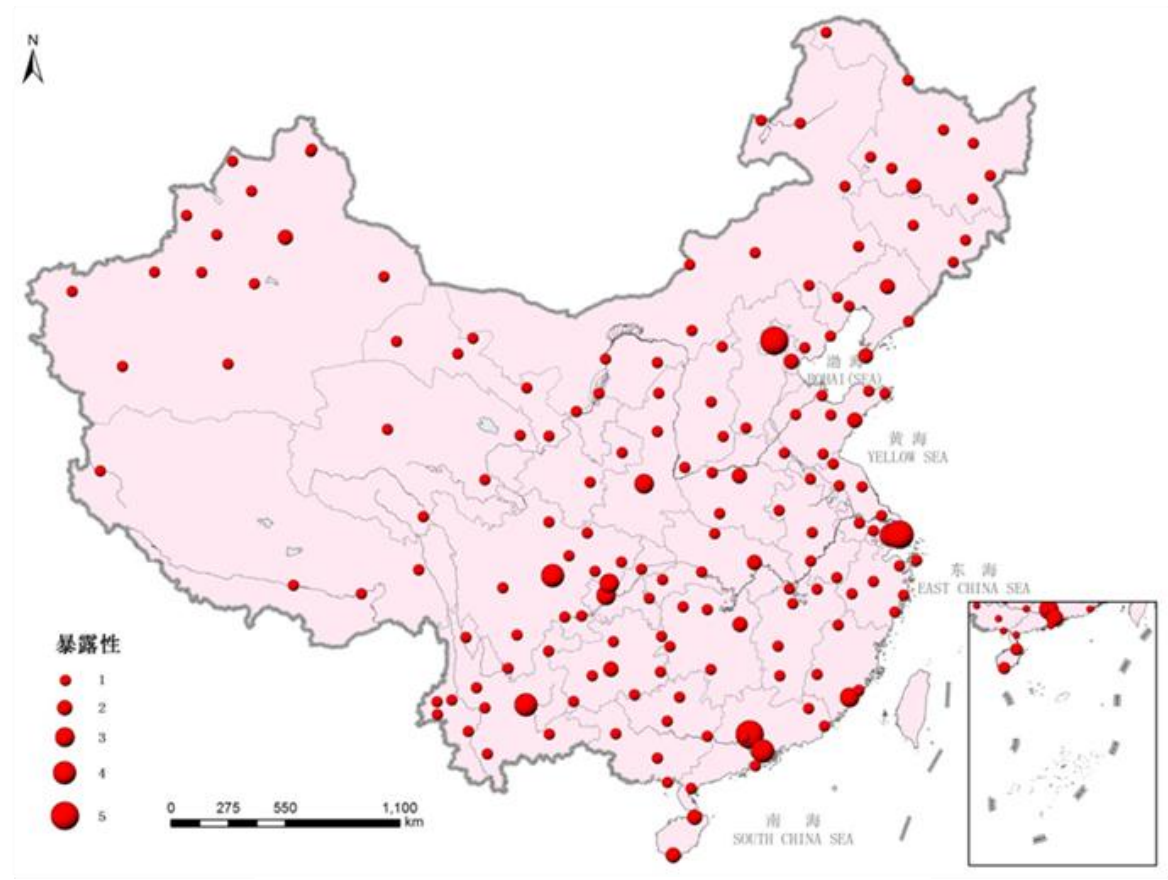

图 2 中国机场暴露性等级分布图

如: 首都国际机场、浦东机场、虹桥机场、白云机 场、咸阳机场、长水国际机场等机场, 在灾害下的 暴露度异常大, 如: 长水国际机场的暴露度是全国 机场平均暴露度的 6.7 倍, 首都机场的暴露度是全 国机场平均暴露度的 18 倍。暴雨发生时, 机场航班

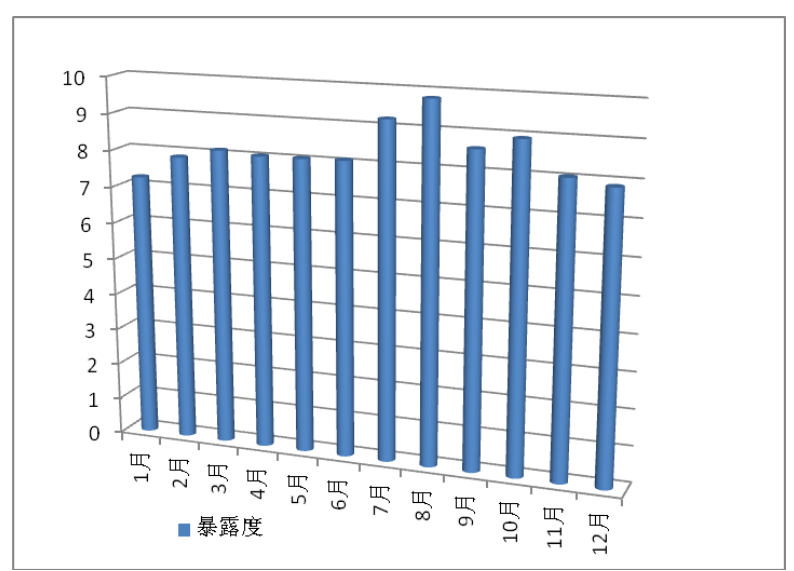

多, 与其他机场的联系密切, 影响范围也比小机场 大。从时间上分析, 中国机场月平均暴露性也有较 明显的季节差异，从 7 月到 10 月，中国机场的暴露 性比其它月份较高, 8 月的暴露度最高, 如图 3。

\section{3. 机场暴雨脆弱性分析}

如图 4, 机场暴雨脆弱性等级分布, 达到五级的 机场一共有 5 个: 广西的福成机场、湖南的永州机 场、云南的阿里机场、黑龙江的伊春机场和首都国 际机场。脆弱性为 4 级的机场较多, 除周水子机场、 榆阳机场等几个机场外, 主要都分布在长江流域, 如：荷花机场、九江机场。

图 3 中国机场月平均暴露度 


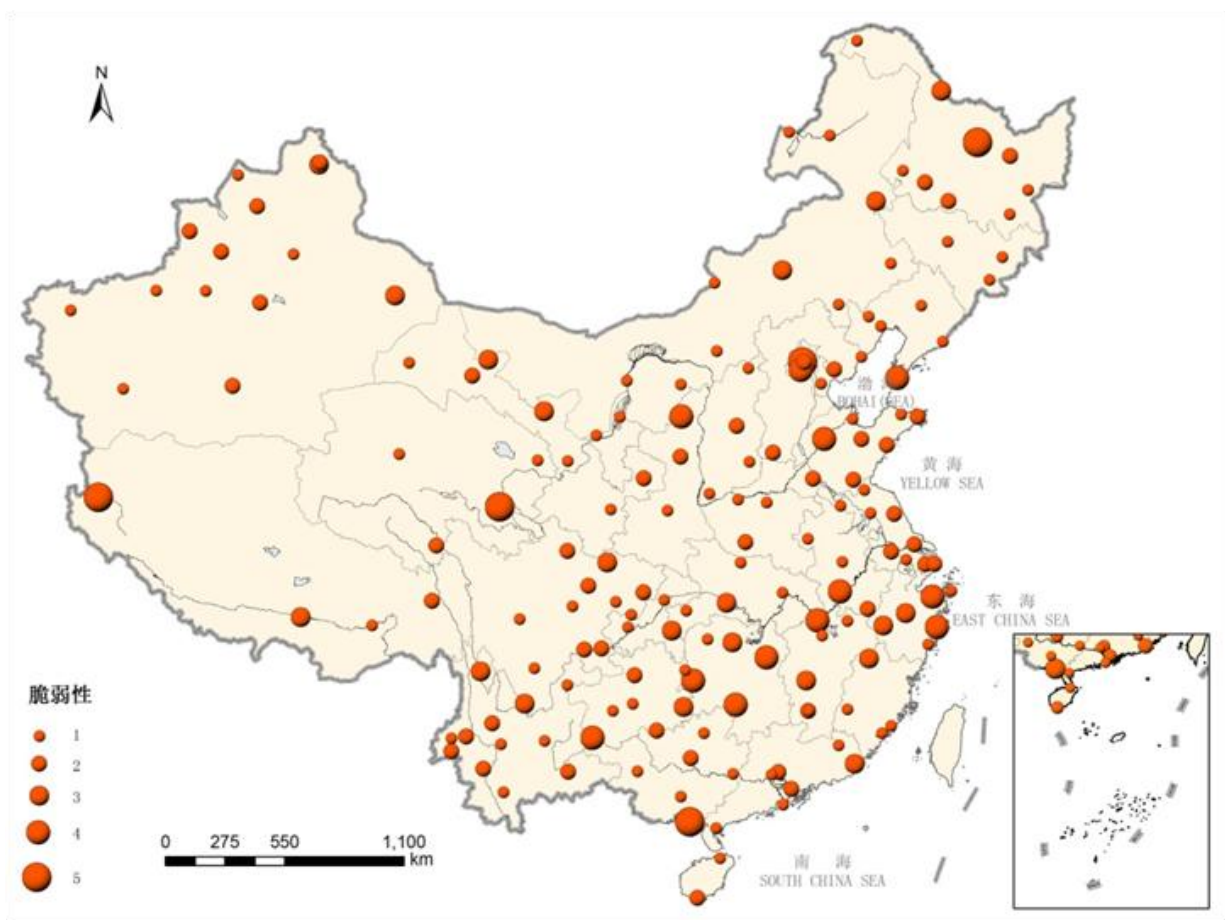

图 4 中国机场脆弱性等级分布图

\section{4. 机场防灾减灾能力分析}

由机场的排水系统, 跑道等作为机场等级评价 标准，机场等级越高对不同程度的暴雨有较高的应
对能力。比如: 增加跑道长度有利于在降落时气象 条件不佳、刹车反推失效或错过最佳接地点的情况 下避免冲出跑道, 亦有利于在紧急中断起飞的情况 下利用剩余跑道长度减速刹车。如图 5 , 我国达到 5

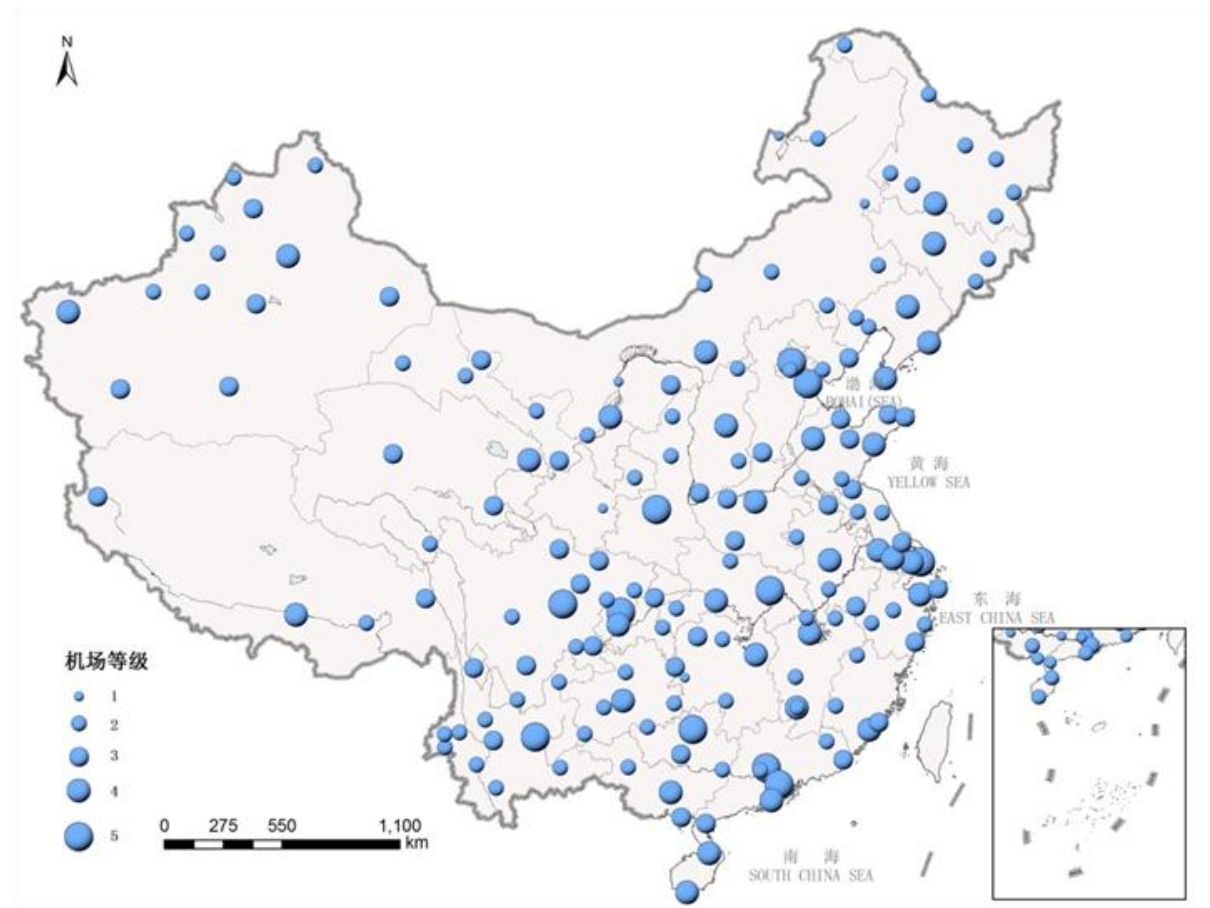

图 5 中国机场防灾减灾能力等级分布图 
级 (4F 等级) 的机场有 11 个,有较强的防灾减灾能 力。如: 首都国际机场、浦东国际机场、白云国际 机场、宝安国际机场、萧山国际机场、长水国际机 场、天河国际机场、双流国际机场、咸阳国际机场、 滨海国际机场、禄口国际机场、两江国际机场。机 场等级为 4 级的机场一共有地窝堡机场、龙嘉机场、 长乐机场等 20 多个机场。

\section{5. 中国机场暴雨灾害风险等级分析}

\subsection{1. 中国机场暴雨灾害风险分析}

如图 6, 暴雨危险性与暴雨灾害风险呈现非常 明显的正相关关系, 中国民航暴雨高风险主要由于 致灾因子 (暴雨) 高危险性起着主要作用, 但这种
和东部地区的机场暴雨灾害风险所有上升，首都国 际机场由于暴露度有所上升, 暴雨灾害风险较高; 周水子机场的脆弱性较高, 同样在暴雨灾害风险等 级区划中突显出来。但是中国西南, 西部和北部地 区的机场暴雨灾害风险普遍较低。

6 月份中国大部分地区进入雨季, 全国暴雨危 险性上升, 暴雨灾害风险也全国性上升。中国南部、 东部、东北部地区机场的暴雨灾害风险水平较高, 暴雨灾害风险较高的机场有 18 个, 占全国所有机场 的 $10.06 \%$; 而暴雨灾害高风险机场有 21 个, 占全 国机场的 $12.42 \%$ 。另外, 遥墙机场和周水子机场两 个机场虽然暴雨危险性较低, 但脆弱性较大, 并且 防灾减灾能力较弱, 同样成为暴雨灾害高风险机场。

7月中国机场暴雨灾害高风险区继续向北推进,

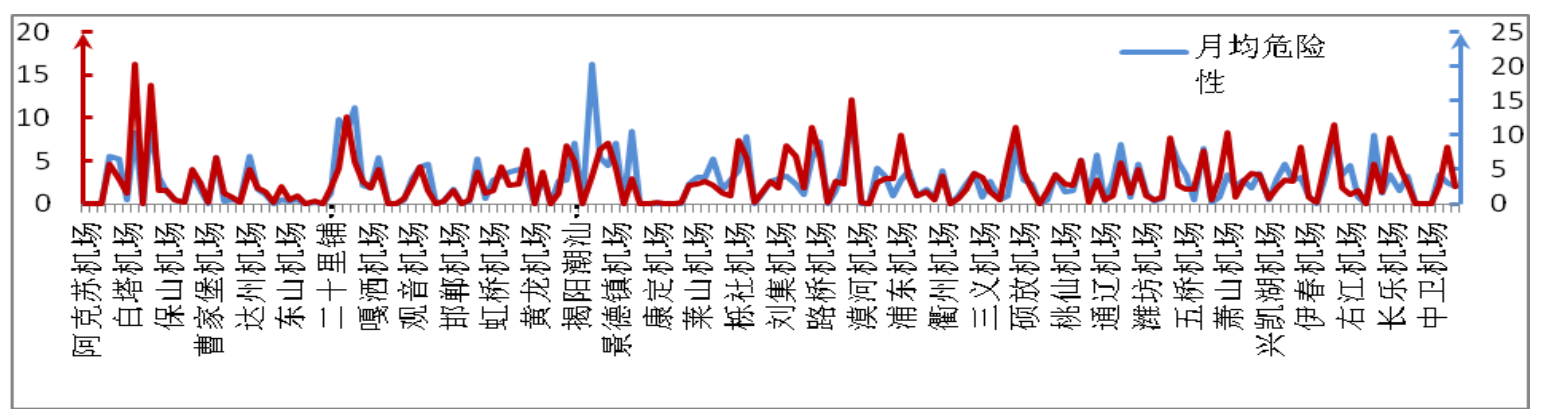

图 6 中国机场月平均暴雨灾害风险与危险性对比

趋势也不是绝对的, 如: 永州机场、金湾机场、栎 社机场、井冈山机场等, 在暴雨月均危险性较低的 情况下, 暴雨灾害风险仍然相对较高。结合图 3-5 分析可得, 首都国际机场、白云机场、浦东国际机 场等较大型机场除了致灾因子外, 机场的暴露性起 着很重要的作用; 永州机场、栋社机场、井冈山机 场等脆弱性等级较高, 使得整体灾害风险值较大; 而三义机场、南充机场、姜营机场等防灾减灾能力 较低, 脆弱性等级高, 即使暴雨危险性较低, 其暴 雨灾害综合风险等级同样很高。

\subsection{2. 中国机场暴雨灾害风险的月变化}

如图 7, 每年的 10 月至次年的 4 月均为全国性的暴 雨灾害低危险性时段, 同样也是全国机场暴雨低风 险时段。5 月到 9 月暴雨灾害高风险中国机场分布 较广, 且高风险分布随着季节变化明显。

4 月开始中国南部个别机场 (如: 佛山机场、 宝安机场、井冈山机场等) 随着暴雨危险性上升, 成为暴雨灾害高风险机场。5 月份中国东南部地区
范围扩大到最大。暴雨灾害较高风险机场共有 23 个, 占全国机场数 $13.02 \%$; 暴雨灾害高风险机场共 28 个, 占全国机场数 $16.57 \%$ 。暴雨危险性随中国雨带 向北移动, 长江以北地区暴雨风险上升, 但是江淮 地区暴雨危险性降低, 部分机场的暴雨风险也明显 降低, 如: 永州机场、郡通机场和普者黑机场等。8 月份这种趋势更加明显, 但是总体上暴雨灾害高风 险机场数量与 7 月份相比有所减少。

9 月开始中国雨带随副热带高压南撤, 暴雨危 险性也迅速降低, 暴雨灾害高风险机场主要分布在 东南沿海地区和一些暴露性较大的大机场, 如: 流 亭机场、浦东国际机场、义乌国际机场、永强机场, 佛山机场、美兰机场、首都国际机场和遥墙机场。 从机场角度分析, 部分机场的暴雨灾害风险时段性 较强, 主要集中在 6 至 9 月份, 但灾害风险大, 如: 首都国际机场、浦东国际机场和双流机场等; 部分 机场灾害风险不大，但是全年都有暴雨灾害风险存 在，如：梧州机场、右江机场和梅州机场等。 

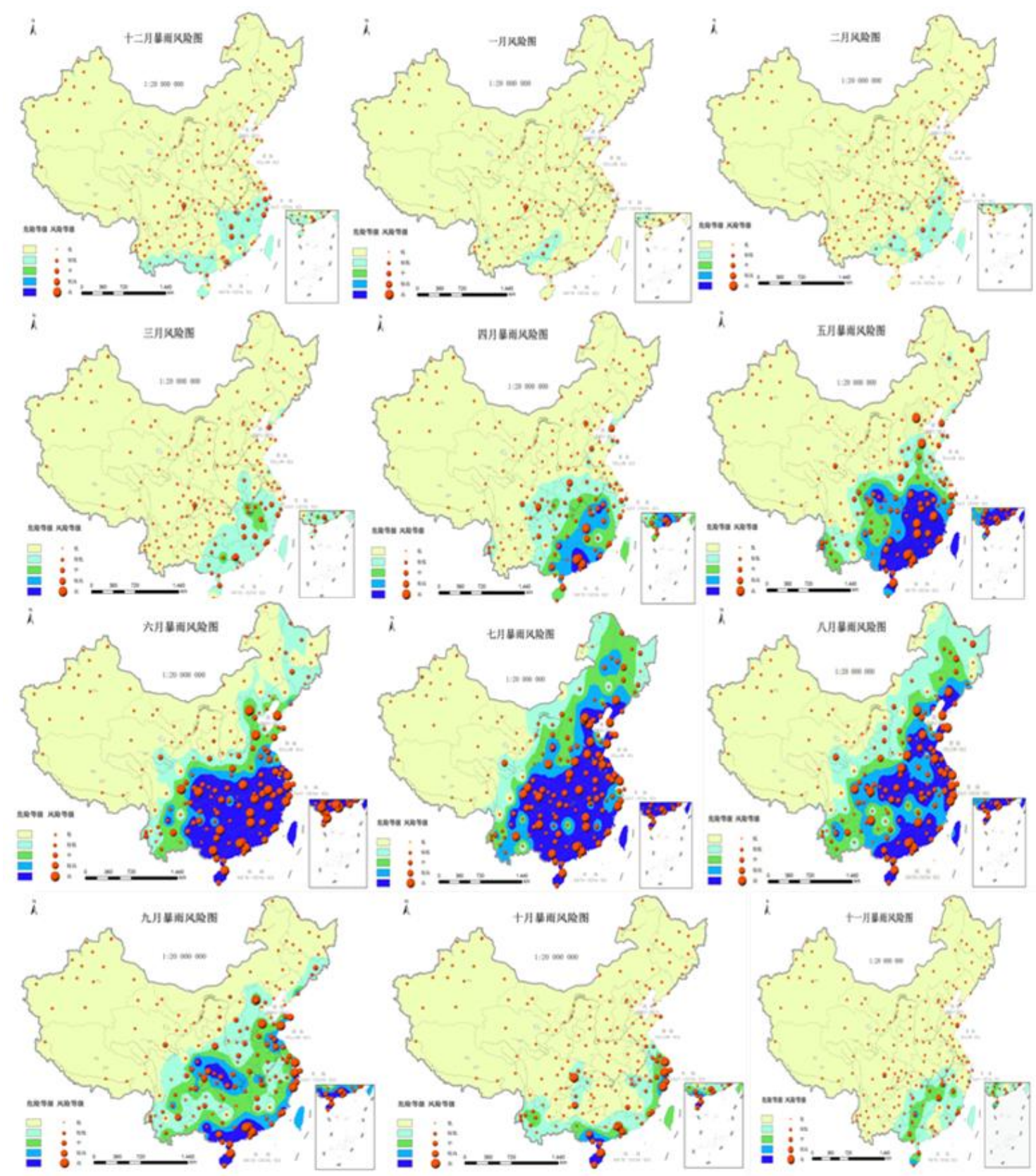

图 7 中国机场暴雨灾害风险区划图

\section{5. 结论}

从风险区划图上看, 中国机场暴雨灾害高风险 分布与中国雨带南北移动有较明显的一致性, 而且 暴雨灾害高风险机场主要分布在东南沿海地区, 东 部、南部地区和北部个别机场; 而西部、西北部地 区的机场暴雨灾害风险较低。暴雨灾害风险评价适 当考虑了机场暴露度、脆弱性和防灾减灾能力突显 出了暴雨灾害发生过程中不同机场的不足之处。机 场可以根据本身暴雨灾害风险的时段特性采取相应 对策。分析中国 2009-2013 年前十的机场重大延误
事件, 其中五件由暴雨引起, 或者与其相关。2012 年 7 月 21 日首都国际机场由于大暴雨导致大面积延 误, 全天取消航班超过 500 架次, 滞留机场的旅客 一度高度 8 万人; 2010 年 7 月 16 日由于暴雨双流 机场两度陷入瘫疾状态, 上万人滞留机场, 同时导 致黄龙机场、咸阳机场, 中甸机场等周边机场出现 较大面积延误。通过上述的中国机场暴雨风险等级 图与近年实际机场延误状况比较, 可以看出, 夏季 暴雨风险指数较高的机场: 首都国际机场、三义机 场、咸阳机场等机场的实际灾情亦最为严重。说明 本研究民航暴雨风险评价结果, 有一定的可信度。 


\section{6. 讨论}

系统、全面、深入地研究暴雨灾害对我国民用 航空安全的影响以及相关的防御规划和措施, 对我 国民用航空业的可持续发展及安全运营具有巨大的 战略意义。其中, 研究我国民用航空系统所面临的 天气灾害风险的等级和区划, 对民航安全能力建设 具有重要的作用。只有在对暴雨灾害风险进行科学 地、系统地分级和区划以后，才能为提高民航系统 防御和应对灾害性天气的能力而做出合理而有效的 规划，提高民航系统运营的安全性。

本文对中国民航暴雨灾害风险的评估方法展开 了初步探索研究, 与传统灾害风险评估的区别在于: 风险评价中的脆弱性主要指机场的功能脆弱性, 并 不是机场相关建筑设施的物理脆弱性; 所评估的内 容是机场的服务功能的在暴雨灾害中的损失风险。 对于民航而言, 虽然, 如地震等巨灾发生时损失可 能非常大, 但是发生的概率非常小。相比而言, 在 日常运营过程中, 频发的气象灾害对机场的影响受 民航相关人员的关注。文章并没有深入挖掘风险指 数与实际灾情的差异, 对于个别机场暴雨灾害风险 计算结果和实际灾情有所出入, 其原因涉及以下几 个问题: 1 民航暴雨灾害风险评价方法仍然在探索 中, 其模型和评价所涉及的指标需要进一步的改进 完善, 以找出更能体现暴雨灾害危险性, 民航暴露 性和防灾减灾能力的指标; 2 收集的风险评估相关 数据的准确性需要进一步确认; 3 另外, 民航脆弱 性评估也有待进一步研究。民航是一个以机场为节 点、航班为链接而相互联系的网络系统, 某一区域 的机场受到灾害的影响后, 该区域以外的其它机场 也可能会由于航班链接而受到间接影响, 如: 2013 年 7 月北京东部地区的暴雨直接造成首都国际机场 大量航班延误取消, 其间接影响是：武宿机场、新 郑机场等几十个机场的延误情况也明显加重。因而 用传统脆弱性评价法 ${ }^{[26-27]}$ 不能有效地评估民航系统 的脆弱性, 因此, 将来在评估民航系统脆弱性时需 要充分利用学科综合特性, 借鉴研究网络系统的相 关理论和方法。

\section{致谢}

本项研究得到了下列基金项目的资助：国家重点
基础研究发展计划（973）项目（项目号： 2012CB955404); 国家中央高校基础研究基金(项目号: 256-105570GK) ；北京师范大学地表过程与资源生态 国家重点实验室自由探索项目基金（项目号： 2015-ZY-05）。

\section{参考文献}

[1] IPCC. 2011. Summary for Policymakers. In: Intergovernmental Panel on Climate Change Special Report on managing the Risk of Extreme Events and Disasters to Advance Climate Change Adaptation. Cambridge University Press, Cambridge, United Kingdom and New York, NY, USA.

[2] 吴吉东,傅宇,张洁,李宁. 1949-2013 年中国气象灾害 灾情变化趋势分析. 自然资源学报,2014,09:1520-1530.

[3] 中国气象局。中国气象灾害年鉴( 2011)。北京：气象 出版社, 2012: 172-177.

[4] 袁艺,马玉玲. 近 30年我国自然灾害灾情时间分布特征 分析. 灾害学,2011,03:65-68+82.

[5] http://www.flightstats.com.

[6] 何勇,何春林. 民航气象预警平台的设计与实现. 空中 交通管理,2008,06:23-25+22.

[7] Brabb E E, Pampeyan E H, Bonilla M G Landslide Susceptibility in San Mateo County, California.US Geological Survey Miscellaneous Field Studies Map MF-360,scale 1: 62500,1972.

[8] Lavalle C, De Roo A, Rarredo J, etal. Towards an European integrated map of risk from weather driven events: a contribution to the evaluation of territorial cohesion in Europe [R]. Technical EUR Reports, EUR, 2005 .

[9] 李世奎,霍治国,王素艳,刘荣花,盛绍学,刘锦銮,马树庆, 薛昌颖. 农业气象灾害风险评估体系及模型研究. 自 然灾害学报,2004,01:77-87.

[10] 霍治国,李世奎,王素艳,刘锦銮,薛昌颖。主要农业气象 灾害风险评估技术及其应用研究。自然资源学 报,2003,06:692-703.

[11] 高晓容, 王春乙, 张继权, 温煦. 东北地区玉米主要气 象灾害风险评价模型研究.中国农业科 学.2014,47(2):4257-4268.

[12] 于飞,谷晓平,罗宇翔,郑小波. 贵州农业气象灾害综合 风险评价与区划。中国农业气象,2009,02:267-270.

[13] 武永峰,张勇,陈鲜艳,尚赞娣,刘布春. 湖南省公路交通 暴雨风险评价研究. 自然灾害学报,2011,05:148-154.

[14] 付桂琴,张文宗. 河北省电网气象灾害风险评价. 中国 气象学会.创新驱动发展 提高气象灾害防御能力 - S3 第三届气象服务发展论坛一公众、专业气象 预报服务技术与应用.中国气象学会: 2013: 6 .

[15] Milan Janic. An assessment of risk and safety in civil aviation . Journal of Air Transport Management. 6 (2000): 43-50.

[16] 李铭, 王淑一, 张宇峰. 民航雷达站雷电灾害风险评估. 黑龙江气象,2012,03:39-40 
[17] 张毝, 郝丽萍, 李子良, 梁燕芳. 民航广汉机场气象能 见度的周期性变化特征的初步分析. 高原山地气象研 究,2009,03:69-72.

[18] 王立倩, 王春玲, 周杰群. 构建民航气象数据库服务系 统运维自动化平台. 气象通信与信息技术委员会、国家 气象信息中心.第 31 届中国气象学会年会 S13 气象通 信与信息技术应用实践与新技术探索.气象通信与信息 技术委员会、国家气象信息中心, 2014: 5 .

[19] 魏学军,姜桓, 王贵明, 孙建战. 雷暴对航空飞行的灾害 分析. 内蒙古气象,2013,04:42-44.

[20] 㚞运晓,罗云,陈庆寿. 区域承灾体脆弱性综合评价指标 权重的确定. 灾害学, 2001,01:86-88.

[21] 中国民用航空局 http: //www.caac.gov.cn/H1/H2/.

[22] 刘刚,基于层次分析法的社区灾害风险脆弱性评价. 兰 州大学学报, 2013,41(4): 102-108

[23] 史培军. 再论灾害研究的理论与实践. 自然灾害学 报,1996,04:8-19.

[24] 张继权, 李宁等。主要气象灾害风险评价与管理数量 化方法及其应用. 北京师范大学出版社. 北京.2007.

[25] Cannon Blaikie, Davis I P T and Wisner B. At Risk: Natural Hazards. People's Vulnerability, and Disasters . London: Rout ledge, 1994: 141-156.

[26] Burton I, Kates R W White G F. The Environmental Hazard. Oxford Univ. Press, Oxford, 1978.

[27] Blarkre P, Cannon T, Davis I, et al. At Risk: natural hazards, Peoples vulnerability, and disasters. London; Rout ledge, 1994. 